\title{
Helium irradiation induced micro-swelling and phase separation in pyrochlore $\mathrm{Lu}_{2} \mathrm{Ti}_{2} \mathrm{O}_{7}$
}

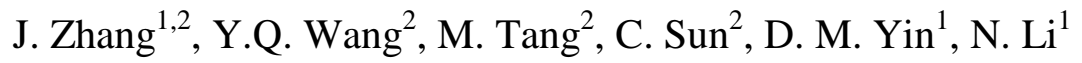 \\ ${ }^{1}$ College of Energy, Xiamen University, Xiamen, Fujian 361005, China \\ ${ }^{2}$ Materials Science and Technology Division, Los Alamos National Laboratory, \\ Los Alamos, New Mexico 87545, USA
}

\begin{abstract}
Polycrystalline pyrochlore $\mathrm{Lu}_{2} \mathrm{Ti}_{2} \mathrm{O}_{7}$ was irradiated with $200 \mathrm{keV} \mathrm{He}{ }^{+}$ions at room temperature to fluences ranging from $2.0 \times 10^{15}$ to $2.0 \times 10^{17} \mathrm{He}^{+} / \mathrm{cm}^{2}$. Irradiation-induced microstructural evolution was examined by grazing incidence X-ray diffraction and crosssectional transmission electron microscopy. A micro-swelling (lattice expansion) induced by cation ion disordering was observed, which an obvious swelling was achieved at a fluence of $2.0 \times 10^{16} \mathrm{He}^{+} / \mathrm{cm}^{2}$, and saturated at a fluence of $1.0 \times 10^{17} \mathrm{He}^{+} / \mathrm{cm}^{2}$ with cation ions fully disordered. Furthermore, during the irradiation process, the pristine pyrochlore phase was found to form by a fluence of $5.0 \times 10^{16} \mathrm{He}^{+} / \mathrm{cm}^{2}$, corresponding to an average ballistic damage dose of $\sim 0.25$ displacements per atom (dpa) for the near surface examined region. No amorphization was observed even to the highest fluence of $2.0 \times 10^{17} \mathrm{He}^{+} / \mathrm{cm}^{2}$. The experimental observations are further discussed in the context of antisite formation in the pyrochlore $\mathrm{Lu}_{2} \mathrm{Ti}_{2} \mathrm{O}_{7}$.
\end{abstract}

Corresponding Author: Jian Zhang, zhangjian@xmu.edu.cn or jianchng@gmail.com 


\section{Introduction}

Crystalline oxides with structures related to fluorite $\left(\mathrm{CaF}_{2}\right)$ have received considerable attention as potential nuclear fuel forms and waste forms [1-5]. Especially, the irradiation resistance to amorphization ability of $\mathrm{A}_{2} \mathrm{~B}_{2} \mathrm{O}_{7}$ pyrochlore structure $\left(\mathrm{P}-\mathrm{A}_{2} \mathrm{~B}_{2} \mathrm{O}_{7}\right)$ has systematically been studied [6,7]. While the irradiation induced micro-swelling (i.e. lattice expansion) has not been paid much attention, swelling of crystalline structure due to irradiation is important for certain practical applications. For instance, in the condition of high level waste (HLW) storage, radiation induced swelling can create micro-cracking, then increase the surface area of radionuclides with surrounding environments, and thus change the leaching rate of the storage matrix [8-10]. Indeed, the irradiation induced micro-swelling has been observed on some actinide compounds through self- $\alpha$ irradiation after a long period of time $[8,11-13]$. To emulate $\alpha$ irradiation induced unit cell swelling from the transuranium $\alpha$ emitter for potential compounds used as high level waste (HLW) disposal waste form, this study aims at systematically examining the micro-swelling behavior of pyrochlore $\mathrm{Lu}_{2} \mathrm{Ti}_{2} \mathrm{O}_{7}$ under He ion irradiations. For the pristine pyrochlore $\mathrm{Lu}_{2} \mathrm{Ti}_{2} \mathrm{O}_{7}$ phase, the cation ions (Lu3+,Ti4+) and "missing $\mathrm{O}$ vacancies" are ordered arranged, while for its parent phase fluorite phase, the cation and ion site will possess equal possibility to be occupied by every cation and $\mathrm{O}$ ions respectively. Here, because of the high chemical durability of titanate-pyrochlore [1], and low ratio of cation Lu to Ti ions, which means high radiation tolerance base on the study by K. E. Sickafus et al. [7], the pyrochlore $\mathrm{Lu}_{2} \mathrm{Ti}_{2} \mathrm{O}_{7}$ sample was used to study. The $P-\mathrm{Lu}_{2} \mathrm{Ti}_{2} \mathrm{O}_{7}$ was irradiated with $200 \mathrm{keV} \mathrm{He}{ }^{+}$ions at room temperature, then the microstructure of irradiated samples was characterized by grazing incidence x-ray diffraction (GIXRD) and cross-section transmission electron microscopy (TEM).

\section{Experimental Procedure}


Polycrystalline $P-\mathrm{Lu}_{2} \mathrm{Ti}_{2} \mathrm{O}_{7}$ samples were synthesized from $\mathrm{TiO}_{2}$ and $\mathrm{Lu}_{2} \mathrm{O}_{3}$ powders (99.99\% purity), by conventional ceramic processing procedures. Pristine sintered pellets were examined using X-ray diffraction and determined to possess the pyrochlore phase structure (S.G. $\# 148, R \overline{3})$ with $a=0.99847(0.00032) \mathrm{nm}$, based on the cubic unit cell description of the $P$ $\mathrm{Lu}_{2} \mathrm{Ti}_{2} \mathrm{O}_{7}\left(V=0.9954 \mathrm{~nm}^{3} /\right.$ unit cell; $\left.\rho_{\text {theoretical }}=7.444 \mathrm{~g} / \mathrm{cm}^{3}\right)$. The measured densities of the sintered pellets (11 $\mathrm{mm}$ in diameter and $\sim 2 \mathrm{~mm}$ in thickness) were approximately $94 \%$ of their theoretical values $\left(\rho_{\text {measured }}=7.01 \mathrm{~g} / \mathrm{cm}^{3}\right)$.

Ion irradiations were carried out at room temperature (RT) in the Ion Beam Materials Laboratory at Los Alamos National Laboratory, using a 200 kV Danfysik High Current Research Ion Implanter. The $200 \mathrm{keV} \mathrm{He}{ }^{+}$ions were implanted at normal incidence to ion fluences ranging from $2 \times 10^{15}$ to $2 \times 10^{17} \mathrm{He}^{+} / \mathrm{cm}^{2}$. The irradiation flux was kept at $\sim 10^{13} \mathrm{He} / \mathrm{cm}^{2} \cdot \mathrm{s}$, where the temperature increase $\Delta T$ in the irradiation samples surface was estimated less than $10 \mathrm{~K}$. The displacement damage and projectile depth profile of the $200 \mathrm{keV} \mathrm{He}{ }^{+}$ions in $P-\mathrm{Lu}_{2} \mathrm{Ti}_{2} \mathrm{O}_{7}$ were estimated using the Monte Carlo code SRIM [14], where the threshold displacement energy of $40 \mathrm{eV}$ were arbitrarily assumed for all elements in the compound. The simulated displacements per atom (dpa) and He ion concentration for the fluence of $1.0 \times 10^{16} \mathrm{He} / \mathrm{cm}^{2}$ are plotted in Figure 1. The projected He range, $R_{p}$, was estimated to be $680 \mathrm{~nm}$ (with target density adjusted to include sample porosity, i.e., using the measured sample density, $\rho_{\text {measured }}$ ), with a longitudinal straggling, $\Delta R_{p}$, of $240 \mathrm{~nm}$, whereas the irradiation peak damage range, $R_{d}$, was estimated to be approximately $600 \mathrm{~nm}$ with a longitudinal straggling, $\Delta R_{d}$, of $320 \mathrm{~nm}$.

Ion irradiated samples were characterized using grazing incidence X-ray diffraction (GIXRD) and cross-sectional transmission electron microscopy (TEM). GIXRD measurements were performed using a Bruker AXS D8 Advanced X-ray diffractometer, $\theta$-2 $\theta$ geometry. The X- 
ray incidence angle for these measurements was set at $\alpha=0.5^{\circ}$, from which we estimated that the X-ray penetration range was within a depth of $200 \mathrm{~nm}$ [15-17], which is significantly shallower than the range of the projected He ions $(\sim 680 \mathrm{~nm})$. Thus, it is believed that these measurements are sampling only the irradiated volume near the sample surface, and the implanted ion chemical effects can be ignored even at the highest fluence of $2.0 \times 10^{17} \mathrm{He} / \mathrm{cm}^{2}$ (He concentration is still lower than 0.3 at.\% in the examined region). The cross-sectional TEM specimen was prepared by conventional mechanical thinning to $\sim 10 \mu \mathrm{m}$, then ion milling to electron transparent. TEM observations were performed using a FEI Tecnai F30 instrument operating with an accelerating voltage of $300 \mathrm{kV}$.

\section{Results}

Figure 2 shows GIXRD patterns obtained from pristine $P-\mathrm{Lu}_{2} \mathrm{Ti}_{2} \mathrm{O}_{7}$ and $P-\mathrm{Lu}_{2} \mathrm{Ti}_{2} \mathrm{O}_{7}$ irradiated with $200 \mathrm{keV} \mathrm{He}{ }^{+}$ions to fluences ranging from $2.0 \times 10^{15}$ to $2.0 \times 10^{17} \mathrm{He} / \mathrm{cm}^{2}$. Fig. 2 indicates that "superlattice" reflection intensities, such as $(111)_{\mathrm{p}},(311)_{\mathrm{p}}$, and $(331)_{\mathrm{p}}$ (marked on the graph), diminish with the increase of irradiation fluence. At lower irradiation fluences of $2.0 \times 10^{15}$ and $2.0 \times 10^{16} \mathrm{He} / \mathrm{cm}^{2}$, the diffraction peaks were observed shifting left to lower 2 theta diffraction angle, corresponding to lattice swelling induced by ion irradiation. While at higher irradiation fluences, the principal diffraction maxima of pyrochlore phase, indexed in Figure 2(a) as $(222)_{\mathrm{P}},(400)_{\mathrm{P}},(440)_{\mathrm{P}}$, and $(622)_{\mathrm{P}}$, begin to split into two peaks by a fluence of $5.0 \times 10^{16}$ $\mathrm{He} / \mathrm{cm}^{2}$. Here, the emerging diffraction pattern can be characterized as fluorite phase (label as $(111)_{\mathrm{F}},(200)_{\mathrm{F}},(220)_{\mathrm{F}}$ and $(311)_{\mathrm{F}}$ in Figure 2(a)). Thus the diffraction of $P-\mathrm{Lu}_{2} \mathrm{Ti}_{2} \mathrm{O}_{7}$ irradiated to a fluence of $5.0 \times 10^{16} \mathrm{He} / \mathrm{cm}^{2}$ at $\mathrm{RT}$ are the mixture of pyrochlore- $\mathrm{Lu}_{2} \mathrm{Ti}_{2} \mathrm{O}_{7}$ and disorder fluorite$\mathrm{Lu}_{2} \mathrm{Ti}_{2} \mathrm{O}_{7}$. These observations suggest that $\mathrm{He}^{+}$ion irradiation of $P-\mathrm{Lu}_{2} \mathrm{Ti}_{2} \mathrm{O}_{7}$ induces a phase separation, from an ordered $P$-phase to a combination of pyrochlore and fluorite phase (marks in Figure 2(b) as " $P$ " and " $F$ " respectively). It is also noteworthy that, the " $P$ " phase peaks are 
suddenly relaxed to the original position and do not shift any more after the phase separation initiated at fluence of $5.0 \times 10^{16} \mathrm{He} / \mathrm{cm}^{2}$. On the other hand, the " $F$ " phase continues swelling with increasing irradiation fluence until saturation. No amorphization transformation was observed even at the highest fluence of $2.0 \times 10^{17} \mathrm{He} / \mathrm{cm}^{2}$ (corresponding to $\sim 1 \mathrm{dpa}$ in the examined depth region).

Figure 3 shows (a) cross-sectional bright-field TEM micrograph obtained from $200 \mathrm{keV}$ $\mathrm{He}^{+}$ion irradiated $P-\mathrm{Lu}_{2} \mathrm{Ti}_{2} \mathrm{O}_{7}$ to fluences of $1 \times 10^{17} \mathrm{He}^{+} / \mathrm{cm}^{2}$, and (b-d) the corresponding high resolution images collected at different irradiation depths. The irradiation layer with a thickness of $\sim 740 \mathrm{~nm}$ shown in BF image (Fig. 3a) is in a reasonable agreement with the ion range of 200 $\mathrm{keV} \mathrm{He}$ ions predicted by SRIM, $R_{p}+\Delta R_{p} / 2(800 \mathrm{~nm})$. In addition, the irradiation damage layer appears to be a two-layer structure: a top brighter layer and a bottom darker layer. Further study reveals that the discrepancy in contrast within the irradiation layer is likely due to helium bubble formation and dislocation loops, which will be examined in more detail in Fig. 3 (b-d) later. The selected area electron diffraction (SAED) patterns captured from the substrate and irradiation layer are inserted respectively. The diffraction from the substrate is consistent with pyrochlore structure with electron along [123] direction, whereas the superlattice diffraction spots are disappeared in the diffraction pattern from the irradiation layer, which is consistent with the disorder fluorite structure.

Figure 3(b-d) shows the HRTEM images obtained from the near surface, the He peak concentration depth, and the interface between the irradiated and the non-irradiated regions, respectively. In Figure 3(d), the image is consistent with a two-phase structure, where the repeat unit of atomic pattern in the top of the interface is smaller than that in the bottom of the interface. According to the inserted fast Fourier transforms (FFT) image obtained from the corresponding HRTEM image regions, the bottom diffraction pattern is consistent with pyrochlore "superlattice" 
structure (same as diffraction pattern from substrate in Figure 3(a), electron beam aligns along [123]), where both the "super diffraction" $(11 \overline{1})_{\mathrm{p}}$ spots as well as the primary diffraction $(22 \overline{2})_{\mathrm{p}}$ of pyrochlore structure are observed. However, the diffraction pattern from the top of the interface is indistinguishable with the cubic fluorite structure (same as the electron diffraction pattern from the irradiation layer in Figure $3(\mathrm{a}))$, only the $(11 \overline{1})_{\mathrm{F}}$ diffraction spot of fluorite can be observed, and no obvious "superlattice" diffraction between diffraction center and $(11 \overline{1})_{\mathrm{F}}$ diffraction spot is found. Thus the Figure 3(d) shows the interface of pristine pyrochlore $\mathrm{Lu}_{2} \mathrm{Ti}_{2} \mathrm{O}_{7}$ and disorder fluorite structure created by the He irradiation. Meanwhile, by measuring the (123) plane distance in the basis of the HRTEM, we found that the lattice swelling from pyrochlore to fluorite structure is approximately $1.77 \%$, in a reasonable agreement with the GIXRD observation to be shown in Fig. 5.

Figure 3(c), captured from the center of the dark region $(680 \mathrm{~nm})$, shows high density of He bubbles with an average diameter of approximately $2 \mathrm{~nm}$. As seen in Fig. 3(a), this defects accumulative area showed darker contrast as compared with the near surface region. While a number of factors can contribute to the difference in the observed image contrast within the damage layer, it is believed that the large number of small He bubbles shown in Fig. 3(c) play an important role in forming the two damage layer structure seen in Fig. 3(a). The He concentration at the depth of ion range $R_{p}, 680 \mathrm{~nm}$, is $\sim 4 \%$ versus $\sim 0.14 \%$ in the near surface layer $(<200 \mathrm{~nm})$ in the sample irradiated to the fluence of $1 \times 10^{17} \mathrm{He} / \mathrm{cm}^{2}$. So even the mobility of He atoms are limited by kinetic energy at room temperature, they still formed small He bubbles and other accumulative defects at the He concentration peak region near $680 \mathrm{~nm}$. On the other hand, no He bubbles were seen from the near surface region in Figure 3(b), where the He concentration as stated above is roughly 30 times lower, presumably below the critical He concentration needed to form bubbles in $P-\mathrm{Lu}_{2} \mathrm{Ti}_{2} \mathrm{O}_{7}$ structure at RT. Finally irradiation induced fluorite pattern is 
observed in Figure 3(b), which possess the same atomic repeat pattern as fluorite $\mathrm{Lu}_{2} \mathrm{Ti}_{2} \mathrm{O}_{7}$ shown in the top of interface in Figure 3(d). The inset diffraction pattern confirms the pattern of Figure 3(b) is consistent with a disorder fluorite structure.

\section{Discussion}

Both GIXRD and TEM results above confirmed that the He ion irradiation induces the phase transformation of $\mathrm{Lu}_{2} \mathrm{Ti}_{2} \mathrm{O}_{7}$ from an ordered pyrochlore to a disorder fluorite structure. Here we discuss this transformation process in the frame of stacking layer model and antisite formation. Figure 4 shows an idealized (unrelaxed) stacking layer model for the crystal structure of pyrochlore $\mathrm{Lu}_{2} \mathrm{Ti}_{2} \mathrm{O}_{7}[18,19]$, where in each unit, the compound consists of 24 layers of cation or anion atoms along the [111] direction of pyrochlore unit cell. The cation layer can be described as fully dense, triangular atom nets, with $\mathrm{Lu}$ or $\mathrm{Ti}$ atoms orderly arranged, whereas the $\mathrm{O}$ layers are based on triangular atom nets, but with fully occupied $\left(\mathrm{O}_{f}\right)$ or orderly missing $\left(\mathrm{O}_{v}\right) \mathrm{O}$ atoms layers. After ion irradiation which fully disorders the cation atoms and $\mathrm{O}$ atoms lattice site (pre-existing oxygen vacancies and fully occupied $\mathrm{O}$ atoms), the lattice becomes indistinguishable from that of an ordinary cubic fluorite structure in the view of diffraction. Therefore, the structure transformation of $P-\mathrm{Lu}_{2} \mathrm{Ti}_{2} \mathrm{O}_{7}$ induced by ion irradiation is apparently due to rearrangement of atoms in cation and anion layers, that is the disorder of cation atoms or antisite defects formation in the $\mathrm{M}$ layer and oxygen atom vacancy disorder in the $\mathrm{O}$ layer. Although, here the GIXRD and TEM provide only information on the disorder of cations (antisite defects), the $\mathrm{O}$ vacancies are thought disordered before the disorder of cations base on the observation by J. Lian et al. [20]. 
The GIXRD observation in Figure 2 indicates $P-\mathrm{Lu}_{2} \mathrm{Ti}_{2} \mathrm{O}_{7}$ unit cell swell before the fluorite transformation takes place. This is because the pyrochlore to fluorite phase transform is initiated from the antisite cation defects formation. When atoms on one sublattice exchange position with atoms on the other sublattice, an antisite pair forms, $A_{A}+B_{B} \rightarrow A_{B}+B_{A}$, where $A_{B}+B_{A}$ is an antisite pair (the $A_{B}$ represent $A$ atoms at the $B$ sublattices, and $B_{A}$ represent $B$ atoms at $\mathrm{A}$ sublattices, as shown in Figure 4 antisite defect layer). In the case of $\mathrm{Lu}_{2} \mathrm{Ti}_{2} \mathrm{O}_{7}$, antisite reaction can be expressed as $L u_{L u}{ }^{\times}+T i_{T i}{ }^{\times} \rightarrow L u_{T i}{ }^{\prime}+T i_{L u}{ }^{\prime}$ by using Kröger-vink notation [21], and the $L u_{T i}{ }^{\prime}+T i_{L u} \cdot$ antisite formation was recently found to correlate directly with lattice swelling [22]. Meanwhile, in Figure 2 the diminishing superlattice reflection (such as $\left.(111)_{p},(331)_{p}\right)$ intensity is primarily indicative of cation disordering, the formation of antisites ( $L u_{T i}{ }^{\prime}$ and $T i_{L u}{ }^{\prime}$ defects). So the pre-transformation cation antisite formation is attributed to the swelling before the pyrochlore to fluorite phase transformation occurred. The lattice parameter swelling versus ion irradiation fluence is plotted in Fig. 5. The calculation is in the basis of the primary peaks from the GIXRD measurements, while the error bars are the average values and the standard deviation of primary peaks. It shows that the swelling linearly increases with irradiation fluence to $\sim 2 \%$ at $\sim 1.0 \times 10^{17} \mathrm{He} / \mathrm{cm}^{2}$, then saturates to this value of $2 \%$ until the highest fluence of $2.0 \times 10^{17} \mathrm{He} / \mathrm{cm}^{2}$. This observation reveals that the cation disordering induced by irradiation increase linearly with irradiation dose until fully disordering (50\% of cation ions randomly exchange position). So the antisite formation rate per unit cell with 88 atoms is 0.1 antisite per fluence of $10^{15} \mathrm{He}^{+} / \mathrm{cm}^{2}$.

Another interesting aspect of the results presented here is the phase separation initiated by the fluence of $5.0 \times 10^{16} \mathrm{He} / \mathrm{cm}^{2}$, where the swelling pyrochlore separates into swelling fluorite phase and no-swelling pristine pyrochlore phase. This phase separation behavior after the lattice swelling to our best knowledge has not been reported before at least in $P-\mathrm{Lu}_{2} \mathrm{Ti}_{2} \mathrm{O}_{7}$ structure. 
After the initial phase separation, the fluorite phase continues to swell, while the separated pyrochlore phase shows no sign of swelling following higher irradiation fluences used in this work. At the same time, the superlattice reflections intensities of $P-\mathrm{Lu}_{2} \mathrm{Ti}_{2} \mathrm{O}_{7}$, e.g. $(111)_{\mathrm{p}}$ and $(331)_{p}$ etc. continuously decrease when the fluence increases to the highest irradiation fluence of $2.0 \times 10^{17} \mathrm{He}^{+} / \mathrm{cm}^{2}$. The continuous decrease in pyrochlore diffraction peak intensity without an observable peak shift implies that the pyrochlore disordering mechanism in the presence of a fluorite phase is different from its pure pristine pyrochlore phase. While similar phase relaxation phenomenon was observed for the $400 \mathrm{Ne}$ irradiation $P-\mathrm{Lu}_{2} \mathrm{Ti}_{2} \mathrm{O}_{7}$ [22], where the authors observed the $P-\mathrm{Lu}_{2} \mathrm{Ti}_{2} \mathrm{O}_{7}$ swelled with the Ne irradiation fluences increase, however, as the amorphization happens, the swelling pyrochlore peaks are relaxed to the pristine positions. Further experiments and modeling efforts are in progress to understand this observed phase separation phenomena in the pyrochlore structure. Finally, no amorphization is observed in all the irradiated samples by either GIXRD or TEM in this study.

\section{Conclusions}

In summary, we have observed an irradiation-induced micro-swelling in $P-\mathrm{Lu}_{2} \mathrm{Ti}_{2} \mathrm{O}_{7}$ and subsequently order-to-disorder (O-D) crystal structure transition from pyrochlore to disorder fluorite phase following $200 \mathrm{keV} \mathrm{He}{ }^{+}$ion irradiation at room temperature. The micro-swelling was found to linearly increase with the fluence until the fully cation disordering and corresponding anion vacancies disordering are reached at the fluence of $1.0 \times 10^{17} \mathrm{He} / \mathrm{cm}^{2}$. The $\mathrm{O}-$ D transformation of the whole sampls was initiated by a fluence of $5.0 \times 10^{16} \mathrm{He}^{+} / \mathrm{cm}^{2}$, which accompanying the pristine pyrochlore phase emerging, and nearly completed at the high fluence of $2.0 \times 10^{17} \mathrm{He}^{+} / \mathrm{cm}^{2}$. The cross-section HRTEM revealed the swelling of $1.77 \%$ from the ordered pyrochlore to a disorder fluorite structure transition, in a reasonable agreement with the GIXRD observations ( 2\%). Finally, we observed the swelling $P-\mathrm{Lu}_{2} \mathrm{Ti}_{2} \mathrm{O}_{7}$ phase separated into 
a swelling fluorite phase and a pristine pyrochlore phase beginning at a fluence of $5.0 \times 10^{16}$ $\mathrm{He} / \mathrm{cm}^{2}$. The pyrochlore disordering mechanism in the presence of a fluorite phase appears different from its pure pristine pyrochlore phase. The further experiments and modeling efforts are in progress to understand this new phase separation phenomena.

\section{Acknowledgements}

This work was sponsored by the National Natural Science Foundation of China with Grant No. 11205128. The work at the Ion Beam Materials Laboratory was partially supported by Center for Integrated Nanotechnologies at Los Alamos National Laboratory. M. Tang would like to thank the financial support of the DOE-NE Materials Recovery and Waste Form Development program including program support from James Bresee, Kimberly Gray, Terry Todd and John Vienna. 


\section{References}

[1] R.C. Ewing, W.J. Weber, J. Lian, J. Appl. Phys., 95 (2004) 5949-5971.

[2] W.J. Weber, R.C. Ewing, C.R.A. Catlow, T. Diaz de La Rubia, L.W. Hobbs, C. Kinoshita, H. Matzke, A.T. Motta, M. Nastasi, E.H.K. Salje, E.R. Vance, S.J. Zinkle, J. Mater. Res., 13 (1998) 1434-1484.

[3] W. Weber, R.V. Ginhoven, L. Corrales, in, 2000.

[4] C. Degueldre, J.M. Paratte, Nucl. Technol., 123 (1998) 21-29.

[5] C. Degueldre, M. Pouchon, M. Dobeli, K. Sickafus, K. Hojou, G. Ledergerber, S. Abolhassani-Dadras, J. Nucl. Mater., 289 (2001) 115-121.

[6] K. Trachenko, J. Phys. Condens. Matter, 16 (2004) 1491.

[7] K.E. Sickafus, L. Minervini, R.W. Grimes, J.A. Valdez, M. Ishimaru, F. Li, K.J. McClellan, T. Hartmann, Science, 289 (2000) 748-751.

[8] F. Goubard, P. Griesmar, A. Tabuteau, J. Solid State Chem., 178 (2005) 1898-1902.

[9] F.W. Clinard Jr, D.L. Rohr, R.B. Roof, Nucl. Instrum. Methods Phys. Res., Sect. B, 1 (1984) 581-586.

[10] W.J. Weber, Radiat. Eff. Defects Solids, 77 (1983) 295-308.

[11] D. Horlait, F. Lebreton, P. Roussel, T. Delahaye, Inorg. Chem., 52 (2013) 14196-14204.

[12] B. Ravat, B. Oudot, N. Baclet, J. Nucl. Mater., 366 (2007) 288-296.

[13] R.C. Ewing, W.J. Weber, F.W. Clinard Jr, Prog. Nucl. Energy, 29 (1995) 63-127.

[14] J.F. Ziegler, J.P. Biersack, U. Littmark, Stopping and range of ions in solids, Pergamon Press, New York, 1985.

[15] G. Lim, W. Parrish, C. Ortiz, M. Bellotto, M. Hart, J. Mater. Res., 2 (1987) 471-477.

[16] H. Dosch, Phys Rev B Condens Matter, 35 (1987) 2137-2143.

[17] J.H. Hubbell, Int. J. Appl. Radiat. Isot., 33 (1982) 1269-1290.

[18] J. Zhang, Y.Q. Wang, M. Tang, J.H. Won, J.A. Valdez, K.E. Sickafus, J. Mater. Res., 25 (2010) 248-254.

[19] K.E. Sickafus, R.W. Grimes, S.M. Corish, A.R. Cleave, M. Tang, C.R. Stanek, B.P. Uberuaga, J.A. Valdez, in, Los Alamos National Lab., Los Alamos, 2006.

[20] J. Lian, L. Wang, J. Chen, K. Sun, R.C. Ewing, J. Matt Farmer, L.A. Boatner, Acta Mater., 51 (2003) 1493-1502.

[21] L. Minervini, R.W. Grimes, K.E. Sickafus, J. Am. Ceram. Soc., 83 (2000) 1873-1878.

[22] Y.H. Li, B.P. Uberuaga, C. Jiang, S. Choudhury, J.A. Valdez, M.K. Patel, J. Won, Y.Q.

Wang, M. Tang, D.J. Safarik, D.D. Byler, K.J. McClellan, I.O. Usov, T. Hartmann, G. Baldinozzi, K.E. Sickafus, Phys. Rev. Lett., 108 (2012) 195504. 


\section{Figure Captions}

Figure 1. The SRIM simulate irradiation damage and ion profile, obtained from $200 \mathrm{keV} \mathrm{He}$ implanting on $\mathrm{Lu}_{2} \mathrm{Ti}_{2} \mathrm{O}_{7}$ to fluence of $1.0 \times 10^{16} \mathrm{He} / \mathrm{cm}^{2}$.

Figure 2. GIXRD patterns obtained from pristine $P-\mathrm{Lu}_{2} \mathrm{Ti}_{2} \mathrm{O}_{7}$ and $P-\mathrm{Lu}_{2} \mathrm{Ti}_{2} \mathrm{O}_{7}$ irradiated with 200 $\mathrm{keV} \mathrm{He}{ }^{+}$ions to a variety of fluences between $2.0 \times 10^{15}$ and $2.0 \times 10^{17} \mathrm{He} / \mathrm{cm}^{2}$ at a fixed grazing incidence angle on the sample, $\alpha=0.5^{\circ}$ (average damage of examined region range from 0.01 $1.0 \mathrm{dpa}$ ). Plots in (a) are linear in intensity. Plots in (b) are the same data as in (a), but shown as logarithmic in intensity. The dot lines in (b) show the primary peak positions of pristine $\mathrm{Lu}_{2} \mathrm{Ti}_{2} \mathrm{O}_{7}$.

Figure 3. Cross-sectional bright-field TEM image and different depth of HRTEM images obtained from polycrystalline $P-\mathrm{Lu}_{2} \mathrm{Ti}_{2} \mathrm{O}_{7}$ irradiated with $200 \mathrm{keV} \mathrm{He}{ }^{+}$ions to fluence of $1.0 \times 10^{17} \mathrm{He} / \mathrm{cm}^{2}$. The FFT diffraction patterns are included as inset in the corresponding HRTEM images.

Figure 4. Schematic diagram shows the stacking layers of pyrochlore $\mathrm{Lu}_{2} \mathrm{Ti}_{2} \mathrm{O}_{7}$ along the [111] axis. In the $\mathrm{Lu}$ or $\mathrm{Ti}$ atoms dominate layer (labeled as Lu layer, Ti layer), dark spheres represent Ti cation with smaller ionic radius, and light spheres represent $\mathrm{Lu}$ atoms. There are total 24 layers per unit cell with distance $a \sqrt{1^{2}+1^{2}+1^{2}}$ ( $a$ is the lattice parameter of cubic pyrochlore), labeled 1 to 24 . The translational registry changes between layers to form a face-centered cubic (fcc) type of stacking (labeled ABCABC. . .). Cation layers are labeled Lu or Ti, which means Lu or Ti dominate metal layer. Anion layers are labeled $\mathrm{O}_{\mathrm{f}}$ or $\mathrm{O}_{\mathrm{v}}$, which represent Oxygen layer is fully occupied or part of $\mathrm{O}$ atoms are orderly replaced by vacancy respectively. There is one vacant layer between two adjacent $\mathrm{O}$ layers. Finally, a schematic antisite defect pair with Lu and Ti atom switch each other position is shown. 
Figure 5. Lattice parameter swelling percentage of $\mathrm{Lu}_{2} \mathrm{Ti}_{2} \mathrm{O}_{7}$ induced by $\mathrm{He}^{+}$ion irradiation at different fluences. 


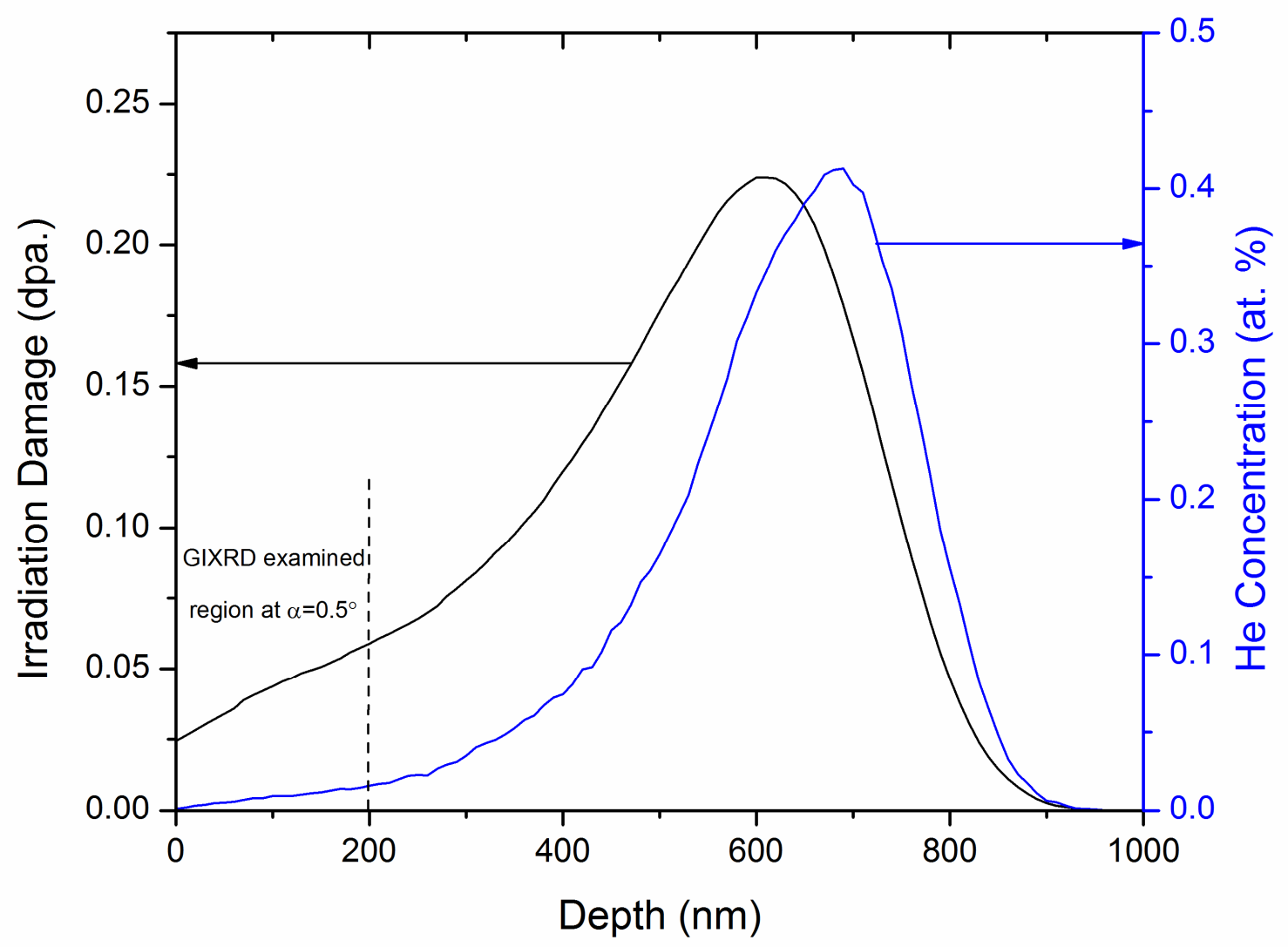

Figure 1 

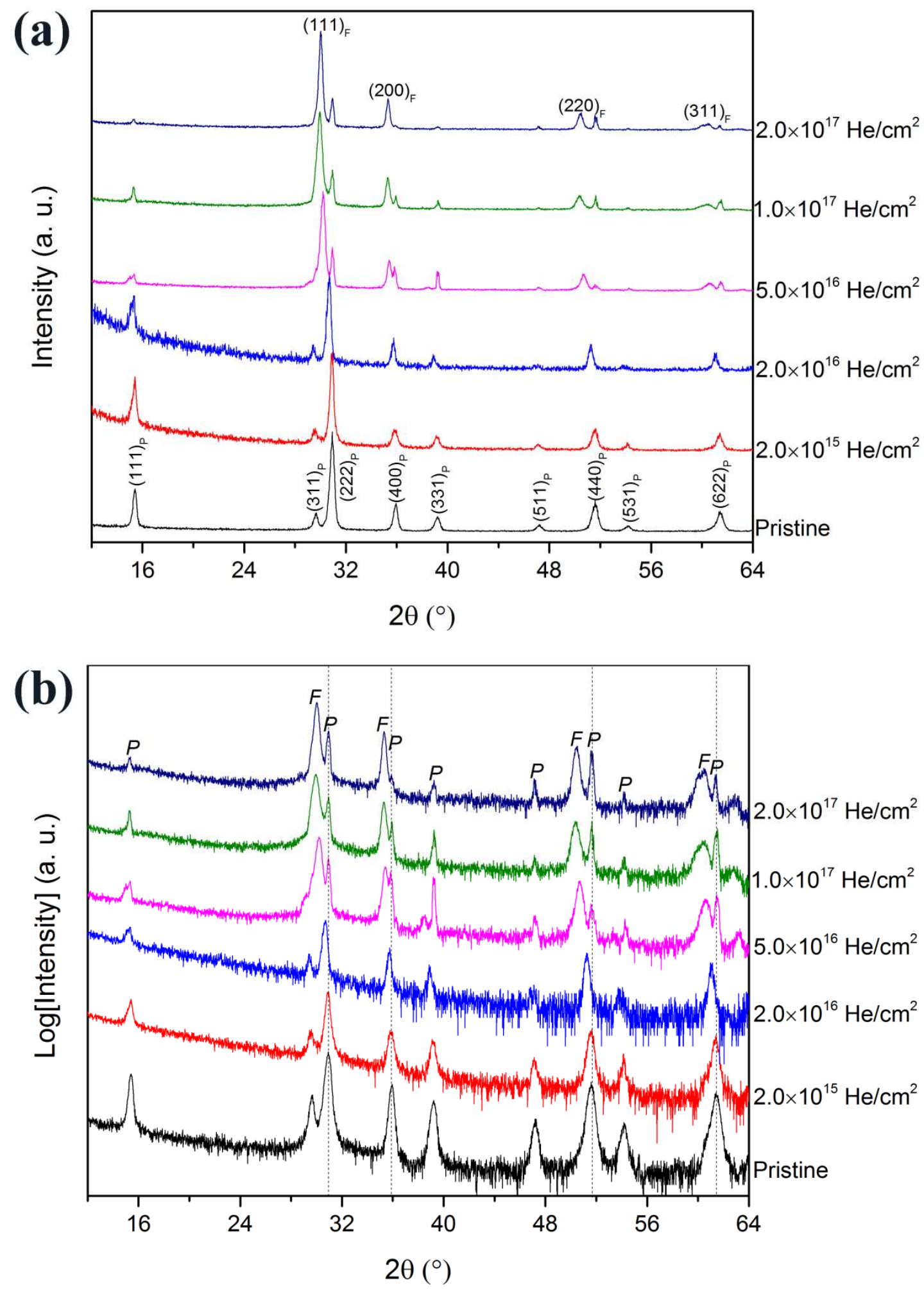

Figure 2 


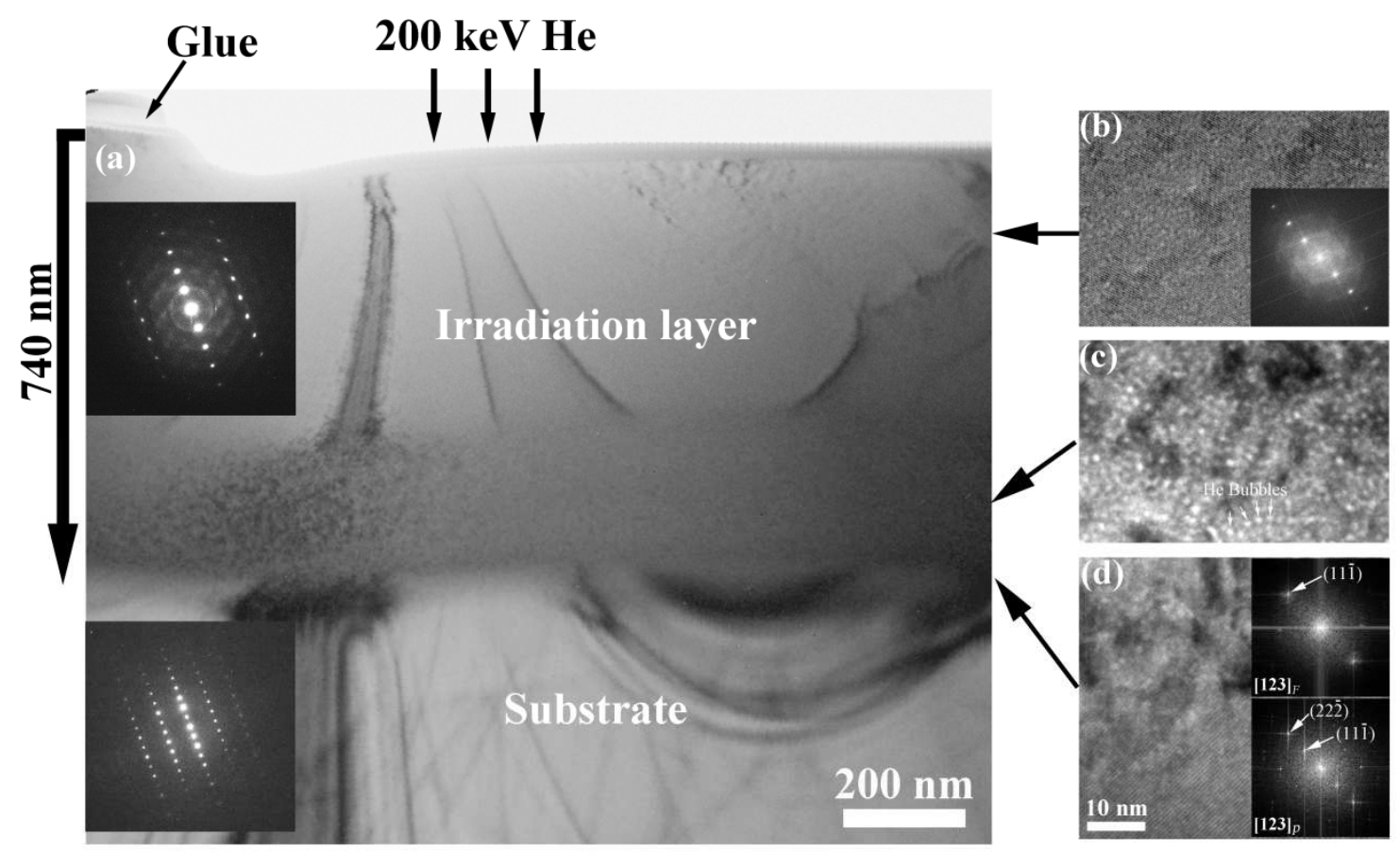

Figure 3 


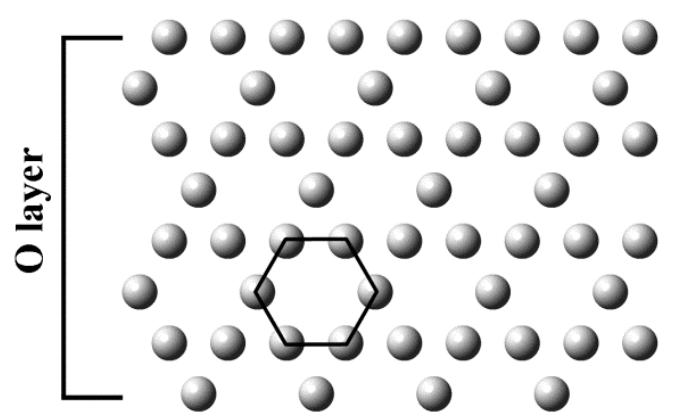

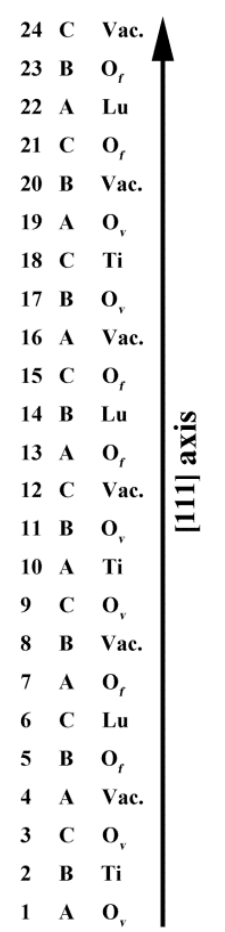

$\begin{array}{ccccccccc}0 & 0 & 0 & 0 & 0 & 0 & 0 & 0 & 0 \\ 0 & 0 & 0 & 0 & 0 & 0 & 0 & 0 \\ 0 & 0 & 0 & 0 & 0 & 0 & 0 & 0 \\ 0 & 0 & 0 & 0 & 0 & 0 & 0\end{array}$

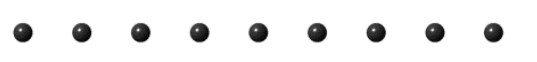

- 0 - 0 - 000

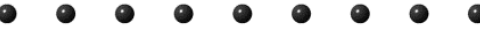

$0 \cdot 0 \cdot 0 \cdot 0 \cdot 0$

- 0 - 0 - $0 \cdot 0 \cdot$

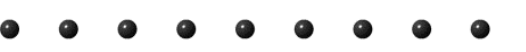

- 0 - 0 - 0

- $\bullet \bullet \bullet-\bullet \quad \bullet \quad \bullet$

- 0 - 0 ○ 0 - 0

- $\bullet \circ \circ / 0$ - $0 \cdot 0 \cdot 0 \cdot 0$

\section{Figure 4}




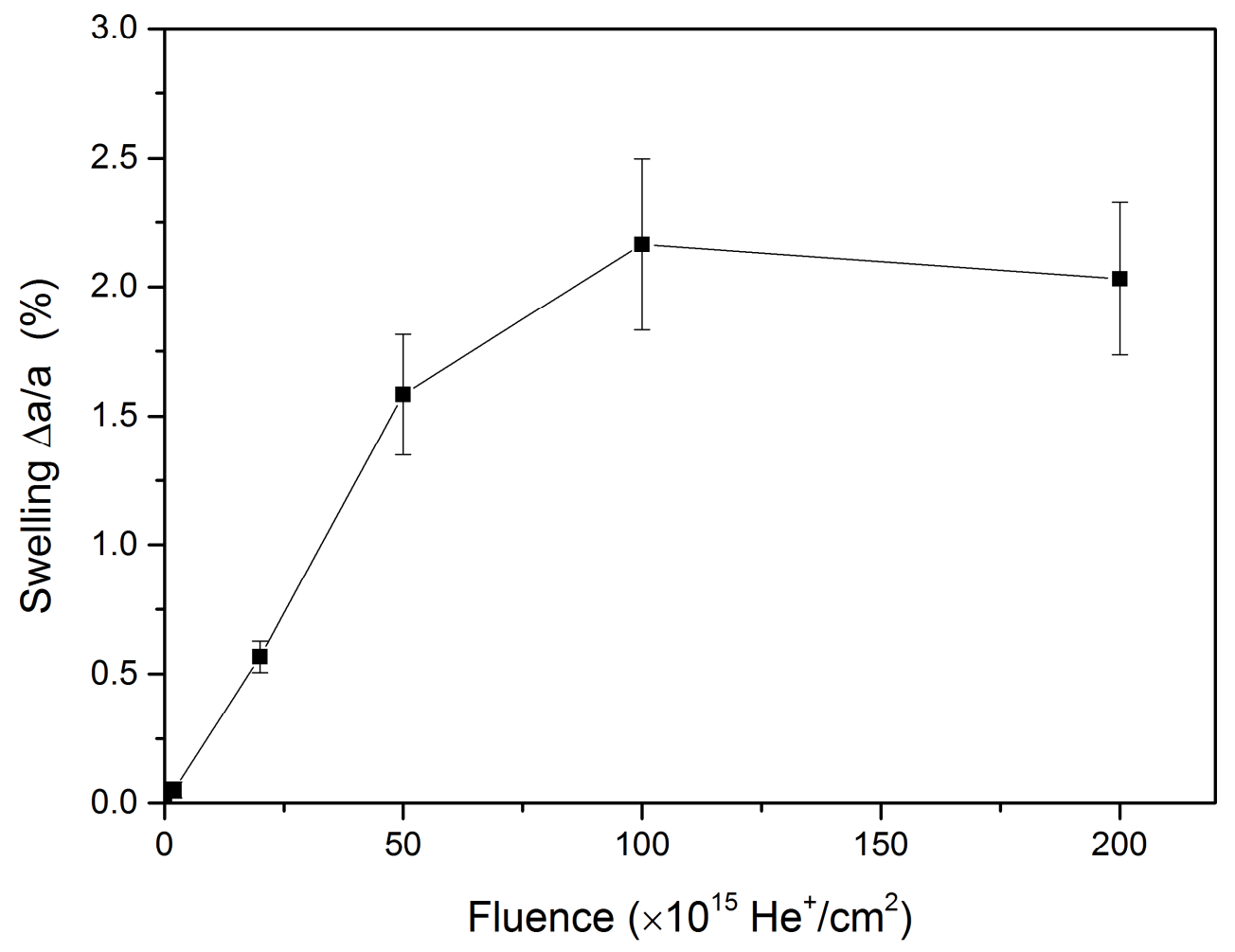

Figure 5

39

40

41

42

43

44

45

46

47

48

49

50

51

52

53

54

55

56

57

58

59

60

61

62

63 